(c) 2020, The Authors. Published by FASS Inc. and Elsevier Inc. on behalf of the American Dairy Science Association ${ }^{\circledR}$. This is an open access article under the CC BY-NC-ND license (http://creativecommons.org/licenses/by-nc-nd/4.0/).

\title{
The relationship between transition period diseases and lameness, feeding time, and body condition during the dry period
}

Ruan R. Daros, ㄴ Hanna K. Eriksson, Daniel M. Weary, and Marina A. G. von Keyserlingk* 둥

Animal Welfare Program, Faculty of Land and Food Systems, University of British Columbia, Vancouver, BC, V6T 1Z4, Canada

\begin{abstract}
In this longitudinal study, we tested the hypothesis that cows that are lame around dry-off are at increased risk of transition diseases (TD), including metritis, subclinical ketosis (SCK), retained fetal membranes, hypocalcemia, or displaced abomasum. We also hypothesized that the relationship between lameness and TD would be mediated through reduced feeding time. We enrolled 461 cows at 9 wk before their expected calving date on 6 commercial freestall farms in the lower Fraser Valley, British Columbia, Canada. Cows were gait-scored weekly using a scale of 1 to 5 . Lameness status was classified based on consecutive gait scores as lame ( 2 consecutive gait scores $=3$ or 1 score $\geq 4$ ) or sound ( 2 consecutive gait scores $\leq 2$ ). Lameness status was summarized as (1) lameness at dry-off (sound or lame); (2) lameness group (always sound $=$ sound on all visits, chronically lame = lame on all visits, and other $=$ changed from sound to lame or vice versa); and (3) proportion of weeks lame during the dry period. Body condition scores were recorded at dry-off and at calving and collectively used to calculate change in body condition for each cow. A subsample of cows $(\mathrm{n}=159)$ was evaluated for feeding time once a week during the dry period. All cows were evaluated for SCK (positive $=\beta$-hydroxybutyrate $\geq 1.2 \mathrm{mmol} / \mathrm{L}$ ) and metritis (positive $=$ foul smell, red/brown watery vaginal discharge) every 3 to $4 \mathrm{~d}$ between $\mathrm{d} 3$ and 17 after calving. We retrieved data on treatment of retained fetal membranes, hypocalcemia, and displaced abomasum during the first $17 \mathrm{~d}$ after calving, cow parity, and milk production in the previous lactation from farm records. We created a binary variable, TD (any of SCK, metritis, retained fetal membranes, hypocalcemia, or displaced abomasum), to differentiate between healthy cows and cows that developed TD. Lameness at dry-off was associated with the occurrence of metritis and TD, but not
\end{abstract}

Received May 16, 2019.

Accepted September 4, 2019.

*Corresponding author: nina@mail.ubc.ca with SCK. Cows that were chronically lame and cows that had an increased proportion of weeks lame during the dry period had higher occurrence of metritis and TD. Lameness was also associated with reduced feeding time, which in turn was associated with increased likelihood of SCK and TD, but not with metritis. Lameness was not associated with change in body condition; however, cows that lost body condition score during the dry period had increased odds of developing SCK, metritis, and TD. Change in body condition was highly associated with body condition score at dry-off. These results suggest that association between lameness and TD is partially mediated through reduced feeding time. Key words: feeding behavior, scan sampling, disease incidence, risk factors

\section{INTRODUCTION}

During the transition period (i.e., \pm 3 wk of calving), dairy cows are at the highest risk of developing infectious and metabolic diseases (Ingvartsen, 2006; Mulligan and Doherty, 2008; LeBlanc, 2010). Changes in metabolism (Bell, 1995; Grummer, 1995) and decreased DMI (Hayirli et al., 2002; Hayirli and Grummer, 2004) in the weeks immediately before calving have been associated with the occurrence of 2 common transition diseases (TD): metritis (Hammon et al., 2006; Huzzey et al., 2007; Dubuc et al., 2010) and subclinical ketosis (SCK; Goldhawk et al., 2009; Ospina et al., 2010).

Reduced DMI during the precalving period may prolong and aggravate negative energy balance during the transition period (Grummer et al., 2004), resulting in fat mobilization (Weber et al., 2013) that triggers a cascade of proinflammatory processes in the adipose tissue and the liver (Sordillo et al., 2009; Contreras and Sordillo, 2011). Increased liver inflammation has been linked to higher occurrence of TD (Bertoni et al., 2008). This may explain the observed association between body condition loss during the dry period and the occurrence of uterine diseases (Chebel et al., 2018) and SCK (Kaufman et al., 2016; Rathbun et al., 2017). Although the etiologies of infectious and metabolic diseases differ, it seems that DMI and body condition loss 
underpin some of the mechanisms that contribute to disease vulnerability.

Lameness has been studied in lactating cows, but little is known about lameness during the dry period and how it relates to TD. Lameness is a common (Solano et al., 2015; Randall et al., 2019) and painful condition (Whay et al., 2005; Chapinal et al., 2010) that has been associated with reduced feeding time and decreased DMI (Bach et al., 2007; Miguel-Pacheco et al., 2014; Weigele et al., 2018). Based on these findings, we propose that lameness during the dry period reduces feed intake, resulting in negative energy balance and greater body condition loss before calving, increasing susceptibility to TD. A study by Calderon and Cook (2011) supports this rationale: cows diagnosed as lame during the $3 \mathrm{wk}$ before calving had higher levels of BHB (a marker for SCK; Duffield, 2000) after calving. Although the association between lameness during the close-up period and TD is to be expected (e.g., Vergara et al., 2014), information is lacking on whether lameness around dry-off also is also associated with TD.

The objectives of this study were to compare the incidence of metritis and SCK between cows that were lame or sound at dry-off, and to explore whether lameness was associated with TD through changes in feeding time and body condition loss during the dry period.

\section{MATERIALS AND METHODS}

This prospective longitudinal study was part of a larger project designed to study lameness epidemiology during the pre- and postpartum periods, and the association between lameness and transition period diseases. All participating dairy farms were located in the lower Fraser Valley region in British Columbia, Canada. Data were collected from May 2017 through January 2018. The project was approved by the Animal Care Committee at the University of British Columbia (protocol A15-0084).

\section{Sample Size Calculation}

We hypothesized that disease incidence would be higher for cows that were lame at dry-off compared with cows that were sound. Based on previous reports on the incidence of metritis ( $20 \%$; Chapinal et al., 2011) we assumed a 10-point difference in incidence between lame (20\%) and sound (10\%) cows. For SCK, we assumed a 15-point difference (30\% incidence for lame cows vs. $15 \%$ incidence for sound cows), because in previous studies the incidence of SCK ranged from 20 to $40 \%$ (LeBlanc, 2010; McArt et al., 2012). Using the sample size formula for testing differences in proportions described by Dohoo et al. (2012), with a power of $80 \%$ and an error rate of $5 \%$, we estimated a sample size of approximately 400 cows (200 in each group, lame or sound) to detect a 10-point difference in metritis cumulative incidence. For SCK, a sample of 242 cows (121 in each group, lame or sound) would be needed to detect a 15-point difference in SCK incidence. We assumed that the effect of lameness on disease incidence would be the same across farms, and we did not account for data clustering, because all outcomes and predictors of interests were measured at cow level (Dohoo et al., 2012).

\section{Farm and Cow Enrollment Criteria}

Farms were pre-selected through a partnership with a hoof-trimming company (AR-PE Hoof Trimming Ltd., Abbotsford, BC, Canada); selection was based on herd size (>160 lactating cows), freestall housing, availability of individual cow records, and willingness to participate in the study. From 9 enrolled farms, 6 were included in this study; on the remaining 3 farms, data on TD was not collected.

On each farm, all parous cows with an expected calving date between July 21 and December 1, 2017, were enrolled 9 wk before their expected calving. A total of 461 cows were initially enrolled, of which 34 were removed before calving. A detailed list of reasons for cow removals is presented in Figure 1.

\section{Farm Data Collection and Description}

A structured interview was conducted with the farm manager during the first visit to each farm. Key aspects about the general herd management and health management of transition dairy cows were recorded. Information about environmental variables, such as type of flooring, number of stalls per pen, and number of feed spaces per pen, was collected through environmental inspection during the first visit. Number of cows in the dry pens was recorded weekly to calculate stocking densities at the feed bunk and the lying stalls. A detailed description of the enrolled farms is presented in Table 1. Average herd size (mean \pm standard deviation) was $361 \pm 137$ lactating cows, and milk production averaged 11,866 $\pm 179 \mathrm{~kg}$ of milk per 305-d lactation.

\section{Gait Scoring and Lameness Definition}

Enrolled cows were gait-scored weekly using a 5-point scale described by Flower and Weary (2006). The weekly gait scores were transformed into weekly lameness status (lame or sound); lameness was defined 
as at least 2 consecutive gait scores of 3 , or 1 gait score $\geq 4$ (Eriksson et al., 2020). Cows were considered sound when 2 consecutive gait scores were $\leq 2$.

To test our primary objective, cows were retrospectively classified as either sound or lame based on their lameness status at the first week after enrollment (hereafter referred to as sound or lame at dry-off). To test our secondary objective (to explore how lameness during the dry period contributes to TD), we established

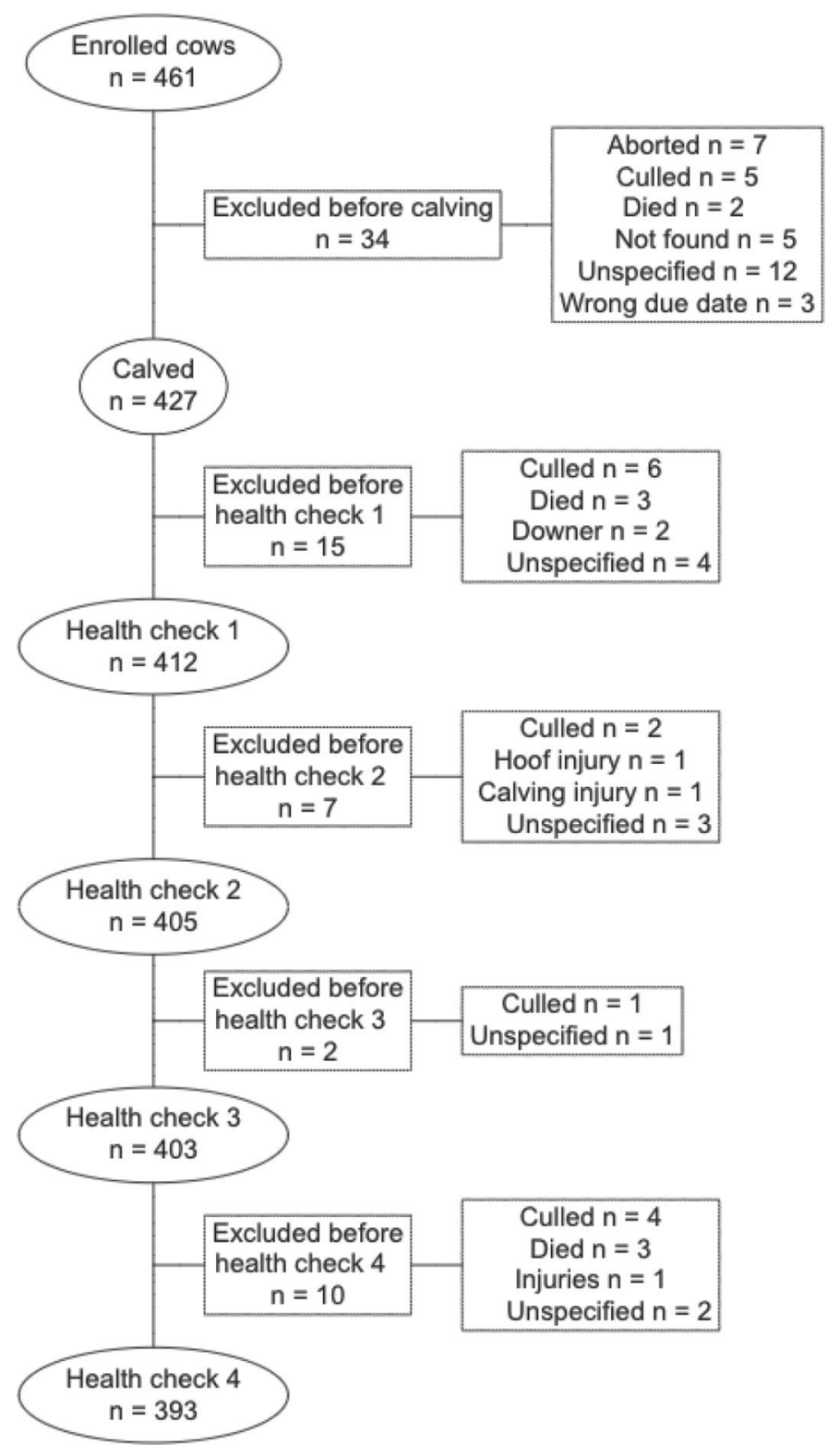

Figure 1. Diagram of cows removed from the study, from top to bottom. Top represents the beginning of the enrollment period $(\sim$ wk 8 before calving), and the bottom represents the end of the study period ( $\sim$ wk 2 after calving).
3 different lameness groups based on the proportion of weeks the cows were lame during the precalving period: chronically lame (cow remained lame during all precalving visits), always sound (cow remained sound during all precalving visits), and other (cow changed lameness status during the dry period; lame to sound or sound to lame). We also created a continuous variable: number of weeks lame divided by total weeks assessed during the dry period.

All gait scores were performed by 2 trained observers (RRD, HKE). A detailed description of gait scoring training and interobserver reliability is reported in Eriksson et al. (2020). Live-scoring interobserver agreement through weighted $\kappa$ was 0.54 and 0.55 before and after the study, respectively.

At each farm visit, all cows identified as severely lame (gait score $\geq 4$ ) were reported to farm personnel, but we did not record whether these cases received treatment.

\section{Body Condition Score and Body Condition Change}

We recorded the BCS of enrolled cows on wk 8, 6, 4, 2,1 , and 0 before their expected calving date, using a 5 -point scale in 0.5 points increments (Ferguson et al., 1994). After calving, cows were assessed for BCS during the first week postpartum, and again between wk 2 and 3 after calving. Because of differences between expected and actual calving date, BCS was summarized as the average BCS wk 8 to 10 before calving (hereafter referred to as BCS at dry-off), and average BCS from the week before calving to $2 \mathrm{~d}$ after calving (hereafter referred to as BCS at calving). We chose to average the BCS at dry-off and at calving to reduce the effect of inter-observer disagreements on the estimates of change in body condition ( $\Delta \mathbf{B C}$; Morin et al., 2017). We further categorized BCS at dry-off and at calving as thin (BCS <3.0), good (BCS 3.0-3.5), and fat (BCS $>3.5$ ). We calculated $\triangle \mathrm{BC}$ during the dry period as the difference between BCS at calving and BCS at dry-off (a positive value indicated that the cow increased her BCS during the dry period). Seven cows did not have data for BCS at dry-off; for these cows, we imputed BCS at dry-off using the BCS assessed on wk $5(\mathrm{n}=6)$ and $4(\mathrm{n}=1)$ before calving.

Four jointly trained observers assigned BCS. Interobserver agreement was calculated with intra-class correlation (ICC), which allows for the inclusion of more than 2 non-random observers of ordinal data (Hallgren, 2012). The ICC was set for 2-way and agreement methods that considered the observer to not be chosen from a random sample of observers, and that BCS scores were in perfect agreement (i.e., penalized more if the BCS were not exactly the same across observers; Hall- 
gren, 2012). Intra-class correlation coefficients take values from 0 (poor agreement) to 1 (excellent agreement); the calculated ICC for the 4 observers was $0.81[95 \%$ confidence interval (CI): 0.73-0.87]. When evaluating ICC the 4 observers independently scored 54 cows on the same day in 1 of the participating farms. While scoring the cows, observers did not share information about the scores assigned. The minimum BCS assigned among the observers was 2 , and the maximum was 5 .

\section{Feeding Time}

Time-lapse cameras (Digital 20 Megapixels Long Range IR; Cuddeback, De Pere, WI) were installed to record the feed bunk of the dry pens on 5 farms every 10 min. On the remaining farm, 3 cameras (CCTV model WVCW504SP; Panasonic, Osaka, Japan) were mounted $6 \mathrm{~m}$ above the feed bunk in the dry pens. These cameras were connected to a digital video surveillance system (GeoVision; GeoVision Inc., Corona,
CA), which recorded video continuously. Videos were scan-sampled every $10 \mathrm{~min}$ to evaluate feeding time. A 10-min scan-sampling protocol has been previously validated for evaluating the feeding time of feedlot cattle (Mitlöhner et al., 2001).

Enrolled cows were individually marked with alphanumeric symbols on their backs to facilitate recognition. Coat color on the back ( $\%$ of black), and face markings were also recorded to facilitate recognition. Differences in cow size on 1 farm made it impossible to determine if small cows were present at the feed bunk. For that reason, a random sample of focal cows $(\mathrm{n}=159)$ was selected from the other 5 farms after the on-farm data collection was completed.

A focal cow was scored as present at the feed bunk if the head was fully over the feed bunk (i.e., ears past the feeding barrier). Daily feeding time in minutes was derived by multiplying the number of images that the focal animal was present during a 24-h period by 10 . Daily feeding time was recorded for each focal cow

Table 1. Farm characteristics and management of the 6 participating freestall dairy farms in the lower Fraser Valley, British Columbia, Canada

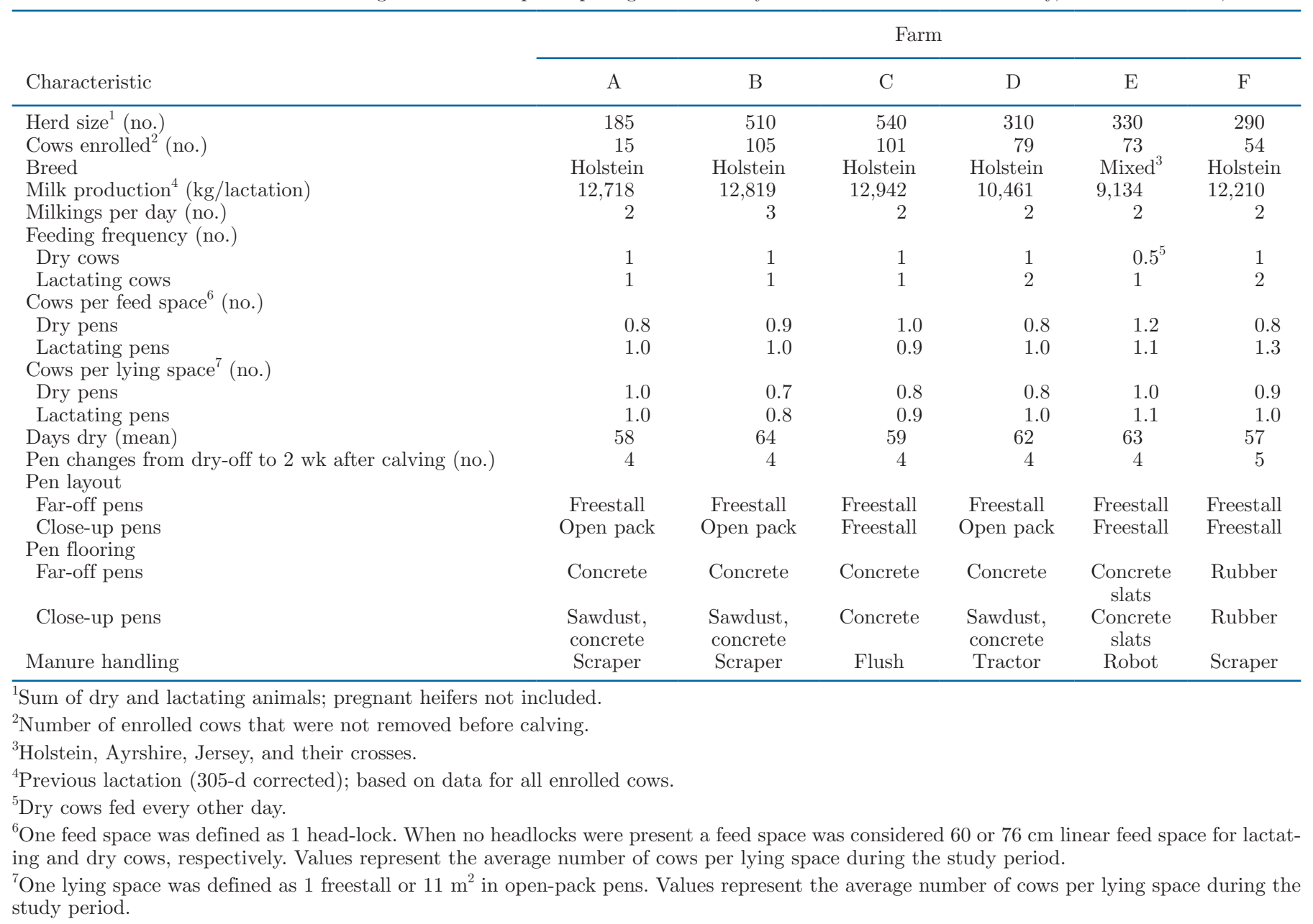


once per wk from wk 8 to 1 before calving. Because of technical issues (e.g., drained camera batteries), or because the cow was moved to another pen (e.g., to the maternity or hospital pen), not all cows had weekly measures of feeding time. On average, the focal cows had feeding time data for $5.6 \pm 1.5 \mathrm{~d}$. A total of 8,337 images (from 23 focal cows from 4 farms) were evaluated for the presence of focal cows by 5 trained observers. The same statistical method as described above for BCS was applied. Calculated ICC for the 5 observers was 0.96 (95\% CI: 0.94-0.97).

\section{Transition Period Diseases}

Enrolled cows were examined for puerperal metritis (hereafter referred to as metritis) and SCK every 3 to $4 \mathrm{~d}$ between $\mathrm{d} 3$ and d 17 after calving, resulting in 4 assessments per animal. Metritis was scored 0 to 4 according to the consistency, smell and presence of pus in cows' vaginal discharge (clear $=0 ;<50 \%$ pus, no fetid smell $=1 ;>50 \%$ pus, no fetid smell $=2$; purulent with foul smell $=3$; red/brown watery fetid smell $=$ 4). As defined by Sheldon et al. (2006), only cows with a metritis score of 4 were considered to have metritis. Subclinical ketosis was diagnosed with a cow-side blood test (BHB $\geq 1.2 \mathrm{mmol} / \mathrm{L}$; Duffield et al., 2009), using handheld FreeStyle Precision Neo ketone monitoring meters (Abbott Diabetes Care Ltd., Witney, UK; validated by Macmillan et al., 2017); blood was collected from the cow's tail vein. We did not assess cows for clinical ketosis, but it is likely that some cows with high levels of BHB were experiencing clinical ketosis. Information about retained fetal membranes, and treatment of hypocalcemia and displaced abomasum during the first 17 DIM was retrieved from farm records. Cows diagnosed with any disease during our health checks were reported immediately to farm staff.

Data collected during the health checks were summarized per cow; cows were considered positive for metritis and SCK if they scored positive for these diseases on at least 1 health check, whether they had another disease or not. Cows that had fewer than 3 health checks and were negative for metritis or SCK were assigned missing values for these diseases. Disease data were further assigned binary categories: healthy, or developing a TD (which included any 1 or a combination of SCK, metritis, treatment of retained fetal membranes, treatment of hypocalcemia, or treatment of displaced abomasum during the first 17 DIM).

In addition to the health checks, 4 of 6 farms routinely performed health assessments during the transition period. These practices varied widely across farms. For example, on 1 farm the farm manager conducted daily assessments, but on another farm health checks were conducted once every $2 \mathrm{wk}$ by the herd veterinarian. Disease treatment also varied widely, but most farms reported using penicillin combined with other therapies (4 of 6 farms) for the treatment of acute metritis. Ketotic cows were treated with propylene glycol on 3 farms, and the remaining farms used oral drenches; in the study region, it is common for oral drenches to include propylene glycol in their formulation, but we did not assess the formulation for the product used. Retained fetal membranes was treated with penicillin on 3 farms, with an intrauterine tetracycline flush on 1 farm, and on a case-by-case basis depending upon veterinary advice on the remaining 2 farms.

\section{Other Cow Variables}

The animals were categorized as primiparous or multiparous based on their parity at dry-off. Because we reported individual data from the pre- and postpartum periods, when referring to data from the postpartum period, parity is referred to as 2nd lactation (for the primiparous at dry-off), and 3 or more lactations (for the multiparous cows at dry-off). We retrieved individual previous corrected 305-d milk yield in kilograms from the last lactation and dry-off date from farm records. Previous milk yield was centered and scaled in reference to the mean of the previous lactational milk yield of all enrolled cows; the values used in analyses represent the standard deviation from the mean.

\section{Statistical Analyses}

All statistical analyses were performed in R 3.5.2 ( $\mathrm{R}$ Core Team, 2019) using the RStudio interface (RStudio Team, 2016). The list of statistical packages used, the commented code and output, original data (in *.Rdata and *.csv formats) and code scripts can be downloaded at https://doi.org/10.5683/SP2/UHWPX9.

All multilevel logistic regression models were fitted through maximum likelihood using an adaptive Gauss-Hermite quadrature method with 12 points to better estimate model parameters (Pinheiro and Chao, 2006). The assumption of linearity between continuous predictors and the log-odds of the outcome variables were assessed graphically. All multilevel linear regression models were fitted through restricted maximum likelihood. The normality and homoscedasticity of lower level residuals were assessed through residual and quantile-quantile plots.

In all models, we estimated confidence intervals (set at 95\%) of model parameters using the profile likelihood method (Venzon and Moolgavkar, 1988). 


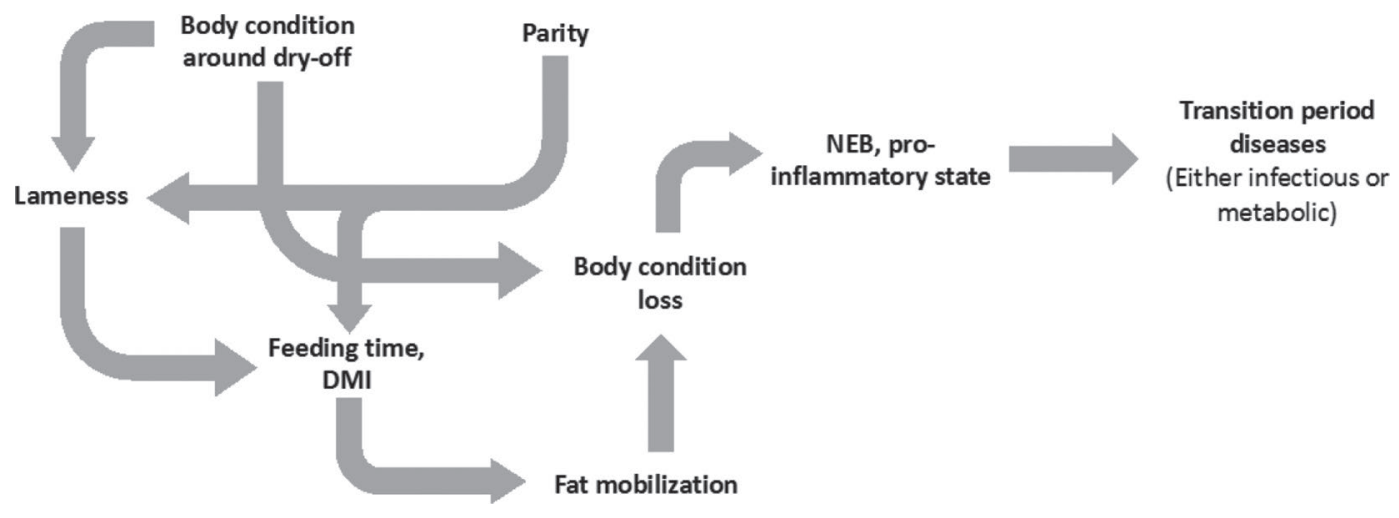

Figure 2. Causal diagram showing the hypothesized causal web linking lameness to transition period disease. NEB = negative energy balance.

Multicollinearity was tested with a variation inflation factor; no variables had a variation inflation factor $>10$ (Dohoo et al., 2012). Plausible biological interactions were tested and kept in the model if $P<0.10$. When inclusion of interaction terms resulted in model convergence failure, we explored the interaction in a separate model (detailed below).

Hypothesis Testing. We tested the association between lameness at dry-off (sound vs. lame) and the occurrence of metritis, SCK, or TD, controlling for known confounders (e.g., parity). For this, we built 3 multilevel logistic regression models with farm as random intercept, 1 for each outcome variable: metritis, SCK, and TD. In these models, we included parity, previous lactation milk production, $\triangle \mathrm{BC}$, BCS at calving, and lameness at dry-off as predictors. In the model for metritis, we also included retained fetal membranes as a predictor. Based on our causal diagram (Figure 2), $\triangle \mathrm{BC}$ should be considered an intervening variable for the association between lameness and TD, and therefore not be included in the models. However, in a preliminary analysis we found that lameness (lameness at dry-off, lameness group, or proportion of weeks lame) was not associated with $\triangle \mathrm{BC}$, allowing us to include $\triangle \mathrm{BC}$ in the models. More details on which variables were associated with $\triangle \mathrm{BC}$ are presented below.

Exploratory Analyses. We also built models for metritis, SCK, and TD similar to those described above, but instead of using lameness at dry-off as predictors, we used lameness group as a predictor in one set of models and proportion of weeks lame during the dry period as predictor in another set of models. These models allowed us to explore the associations between chronic lameness and TD, and the cumulative effect of lameness during the dry period on the incidence of TD. In the models for SCK, the interaction between lameness group and BCS at calving did not converge.
To remove the interaction term, we built separate models to measure the association between lameness and SCK using a subset of data only from fat cows (calving BCS >3.5). The rationale for this analysis was based on the premise that lameness would contribute more to SCK risk in fat cows than in cows with a lower body condition, because low body condition seems to be a protective factor for SCK (Duffield et al., 1998).

In our causal diagram (Figure 2), we proposed that lameness reduces feeding time, and that reduced feeding time (especially during the 3 wk before calving) increases the risk of developing TD. Hence, we built models to test these different parts of the causal diagram. To measure the association between weekly lameness status and weekly feeding time, we built a multilevel linear regression model, including the random intercepts of farm and cow within farm, and using week in relation to calving as the random slope. We used feeding time $(\mathrm{min} / \mathrm{d})$ as the outcome variable, and included lameness status (lame vs. sound), parity, BCS at dry-off, previous lactation milk production, and period (far-off $=$ wk 8 to 4 before calving, and close-up = wk 3 before calving to the week of calving) as predictors. We included period as a predictor because feeding time during the dry period changes at a different rates in the far-off and close-up periods (Grummer et al., 2004).

To assess the relationship between feeding time and the occurrence of disease (metritis, SCK, and TD) we built multilevel logistic regression models similar to what has been described above; in these models, lameness and $\triangle \mathrm{BC}$ were considered intervening variables and not included. Predictors for these models included: feeding time (average per cow using the data available for the 3 wk before calving), parity (primiparous vs. multiparous), BCS at calving (thin, good, and fat), and previous milk production. Cows' BCS at calving did 
not converge because of the low number of thin cows in the data set; BCS at calving was recoded as fat (BCS $>3.5)$ and not fat $(\mathrm{BCS} \leq 3.5)$.

We also built a model to assess the factors associated with $\triangle \mathrm{BC}$. Because $\triangle \mathrm{BC}$ was a continuous variable with no repeated measure (i.e., only 1 measure per cow) we fitted 2 linear multilevel models using farm as a random effect to: (1) measure the associations between $\triangle \mathrm{BC}$ and lameness group (always sound, chronically lame, and other), parity, BCS at dry-off, previous milk production, and number of days dry; and (2) measure the association between $\triangle \mathrm{BC}$ and feeding time, which also included parity, BCS at dry-off, previous milk production, and days dry. For this model, feeding time was averaged per cow across the dry period. We found a nonlinear association between feeding time and $\Delta \mathrm{BC}$ (https://doi.org/10.5683/SP2/UHWPX9); to improve model fit, we created a variable splitting feeding time into 2 categories: low (average feeding time $\leq 4 \mathrm{~h} / \mathrm{d}$ ) and high (average feeding time $>4 \mathrm{~h} / \mathrm{d}$ ). To improve model fit and test the difference in the slopes of feeding time between low and high feeding time, the interaction between continuous feeding time and categorical feeding time was included in the model.

We extracted the residuals from a multilevel logistic regression model that included farm as random effect; the fixed effects of average feeding time in the closeup period, parity, BCS at calving, $\triangle \mathrm{BC}$, and previous lactation milk yield; and the response variable TD. To test if lameness group (always sound, chronically lame, or other) explained some of this residual variation in $\mathrm{TD}$, we fitted a univariable linear regression, using the model residuals as the outcome and lameness group as the predictor. This simple linear regression allowed us to measure the model's coefficient of determination $\left(\mathrm{R}^{2}\right)$, quantifying how much extra variation lameness is explained.

\section{RESULTS}

The proportions of cows that were chronically lame, always sound, or whose lameness status changed during the dry period were 23,33 , and $43 \%$, respectively. Overall disease incidence and disease incidence per lameness group are presented in Table 2. Cows spent an average of $245 \pm 53 \mathrm{~min} / \mathrm{d}$ feeding. Feeding time in relation to lameness status is presented on Figure 3.

\section{Hypothesis Testing}

Parameters estimates and confidence intervals for factors associated with metritis, SCK, and TD are presented in Table 3. Cows that were lame (vs. sound) at dry-off had higher odds of metritis and TD postpartum, but not of SCK. Cows in their third lactation or later had higher odds of SCK and TD, but not of metritis, compared with cows in their second lactation. An increase in BCS from dry-off to calving was associated with reduced odds of metritis, SCK, and TD; BCS at calving was associated only with the odds of SCK. Thin cows (BCS < 3.0) and cows with good BCS (3.0-3.5) at calving had lower odds of SCK than fat cows $(\mathrm{BCS}>3.5)$. Previous lactation milk production was not associated with the odds of metritis, SCK, or TD. Cows with retained fetal membranes after calving had higher odds of metritis than cows that were not diagnosed with retained fetal membranes.

\section{Exploratory Data Analyses}

Lameness and Metritis. Results from the models evaluating lameness as a predictor for metritis occurrence are presented in Table 4. We found a tendency for chronically lame cows to have higher odds of developing metritis than cows that remained sound. This finding

Table 2. Incidence of transition period diseases in the first 3 wk after calving by lameness group in 427 dairy cows from 6 dairy farms in the lower Fraser Valley, British Columbia, Canada

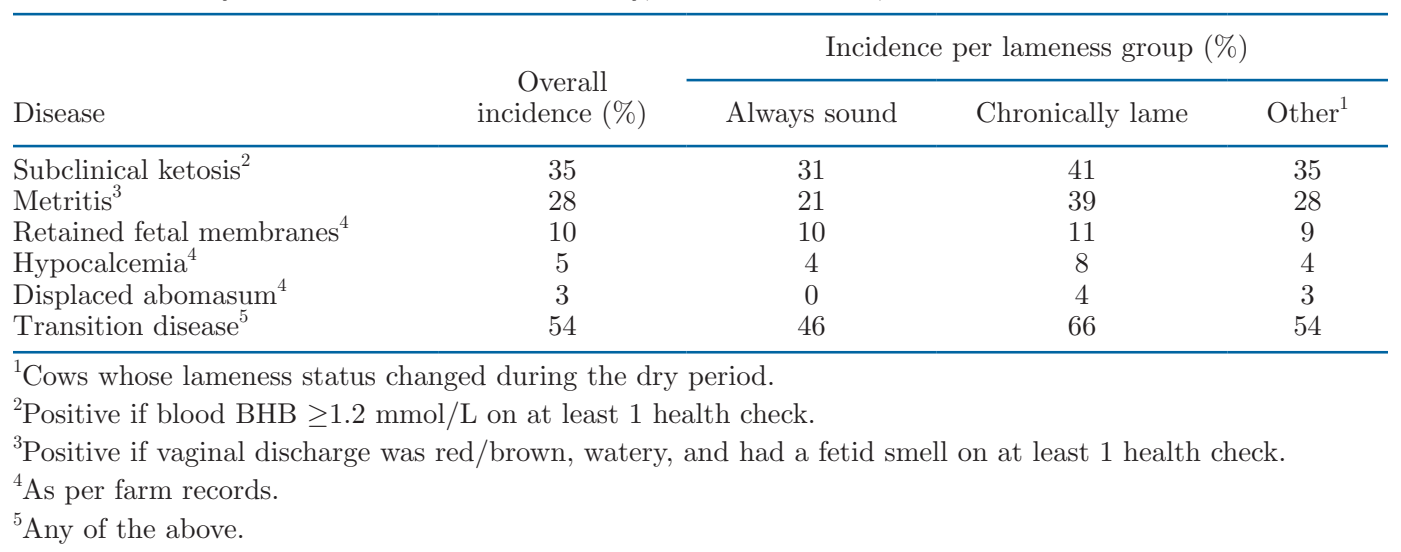




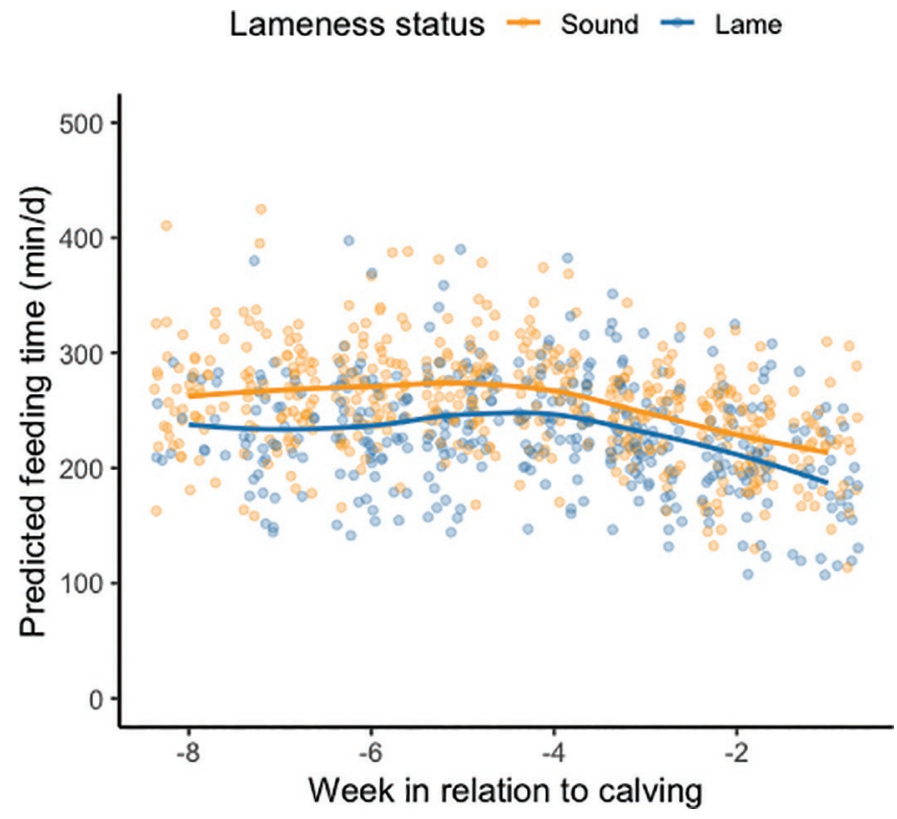

Figure 3. Estimated time spent feeding in relation to week before calving by lameness status of 159 dry cows from 5 commercial freestall dairy farms in the lower Fraser Valley, British Columbia, Canada. Each dot represents the estimated feeding time of each cow observed each week. Dots were jittered using the geom_jitter function, and lines are estimated using the loess method from the geom_smooth function (ggplot2 package; Wickham, 2016). When lame, cows spent an average of $20 \mathrm{~min} / \mathrm{d}(95 \% \mathrm{CI}:-30$ to $-10 \mathrm{~min} / \mathrm{d} ; P<0.01)$ less time feeding than when sound.

was supported by the linear relation between the proportion of weeks lame and the odds of metritis; for each $10 \%$ increase in weeks lame, the odds of metritis increased by 1.07 times. Cows that gained BCS from dry-off to calving had reduced odds of metritis. Body condition score at calving, parity, and previous lactation milk production were not associated with the odds of metritis. Retained fetal membranes were associated with increased odds of metritis. No interactions were retained in any of the models for metritis.

Lameness and SCK. Results from the models evaluating lameness during the dry period as a predictor for SCK are presented in Table 5. Neither the proportion of weeks lame during the dry period nor chronic lameness during the dry period was associated with higher odds of SCK. Gaining BCS during the dry period was associated with reduced odds of SCK, regardless of $\mathrm{BCS}$ at calving. Cows that were thin at calving had reduced odds of SCK compared with cows that were fat. Animals in their third lactation or later had higher odds of having SCK than cows in their second lactation.

When considering only fat cows at calving $(n=108)$, chronically lame cows tended to have higher odds of
SCK [odds ratio (OR) 3.44; $95 \%$ CI: 1.00 to $13.36 ; P=$ 0.06] compared with cows that remained sound. In this model, neither $\triangle \mathrm{BC}$ (OR 0.57; 95\% CI: 0.18 to 1.83 ; $P=0.34$ ), parity (OR $2.17 ; 95 \%$ CI: 0.75 to $6.63 ; P=$ 0.16 ), nor previous milk production (OR $0.69 ; 95 \%$ CI: 0.43 to $1.08 ; P=0.11$ ) was associated with the odds of SCK.

Lameness and TD. Results from the models evaluating lameness during the dry period as a predictor for TD are presented in Table 6. Chronically lame cows had higher odds of TD compared with animals that remained sound. For each $10 \%$ increase in the proportion of weeks lame, the odds of TD increased by 1.09 times. Cows with 3 or more lactations had increased odds of TD compared with cows in their second lactation, and cows that gained BCS during the dry period had reduced odds of TD. Body condition score at calving and previous lactation milk production were not associated with the odds of TD. No interactions were retained in any of the models for TD.

Lameness and Feeding Time. Lameness was associated with reduced feeding time; when lame cows spent on average $20 \mathrm{~min} / \mathrm{d}$ (95\% CI: -30 to $-10 \mathrm{~min} / \mathrm{d}$; $P<0.01$ ) less time feeding than when sound (Figure 3). Also, multiparous cows spent less time feeding $(-19$ $\min / \mathrm{d} ; 95 \%$ CI: -36 to $-3 \mathrm{~min} / \mathrm{d} ; P=0.02)$ than primiparous cows. Compared with fat cows, cows with good BCS and those with thin BCS spent $33 \mathrm{~min} / \mathrm{d}$ (95\% CI: 16 to $49 \mathrm{~min} / \mathrm{d} ; P<0.01$ ) and $35 \mathrm{~min} / \mathrm{d}$ (95\% CI: 6 to $63 \mathrm{~min} / \mathrm{d} ; P<0.01)$ more time feeding, respectively. Previous lactation milk production was not associated with time spent feeding $(6 \mathrm{~min} / \mathrm{d} ; 95 \%$ CI: -1 to $13 \mathrm{~min} / \mathrm{d} ; P=0.09)$ during the dry period. We found an interaction (see Figure 3 ) between week in relation to calving and period (far-off and close-up). During the close-up period, feeding time decreased at a greater rate $(-19 \mathrm{~min} / \mathrm{wk} ; 95 \% \mathrm{CI}:-27$ to $-10 \mathrm{~min} /$ wk; $P<0.01)$ than during the far-off period $(-1.7$ $\min /$ wk; $95 \%$ CI: -7.9 to $3.6 \mathrm{~min} / \mathrm{wk} ; P=0.55)$. We found no interaction between lameness status, week to calving and period.

Feeding Time and TD. Average feeding time during the close-up period (OR 0.8; $95 \%$ CI: 0.5 to $1.1 ; P$ $=0.20$ ), parity (third lactation or later; OR 0.8; $95 \%$ CI: 0.3 to $2.0 ; P=0.64)$, BCS $(\leq 3.5 ;$ OR $1.0 ; 95 \%$ CI: 0.4 to $2.8 ; P=0.98)$ and previous lactation milk production (OR $0.9 ; 95 \%$ CI: 0.6 to $1.4 ; P=0.73$ ) were not associated with metritis.

For each $1 \mathrm{~h}$ increase in average feeding time during the close-up period, the odds of SCK decreased by 0.7 times (95\% CI: 0.4 to $0.9 ; P=0.02)$; cows in their third lactation or later had higher odds of SCK (OR 4.2; $95 \%$ CI: 1.7 to $12.2 ; P<0.01)$ than cows in their second 
Table 3. Parameters from the models for the association between lameness at dry-off and the occurrence of metritis, subclinical ketosis, and transition disease in the first 3 wk after calving in 403 dairy cows from 6 dairy farms in the lower Fraser Valley, British Columbia, Canada

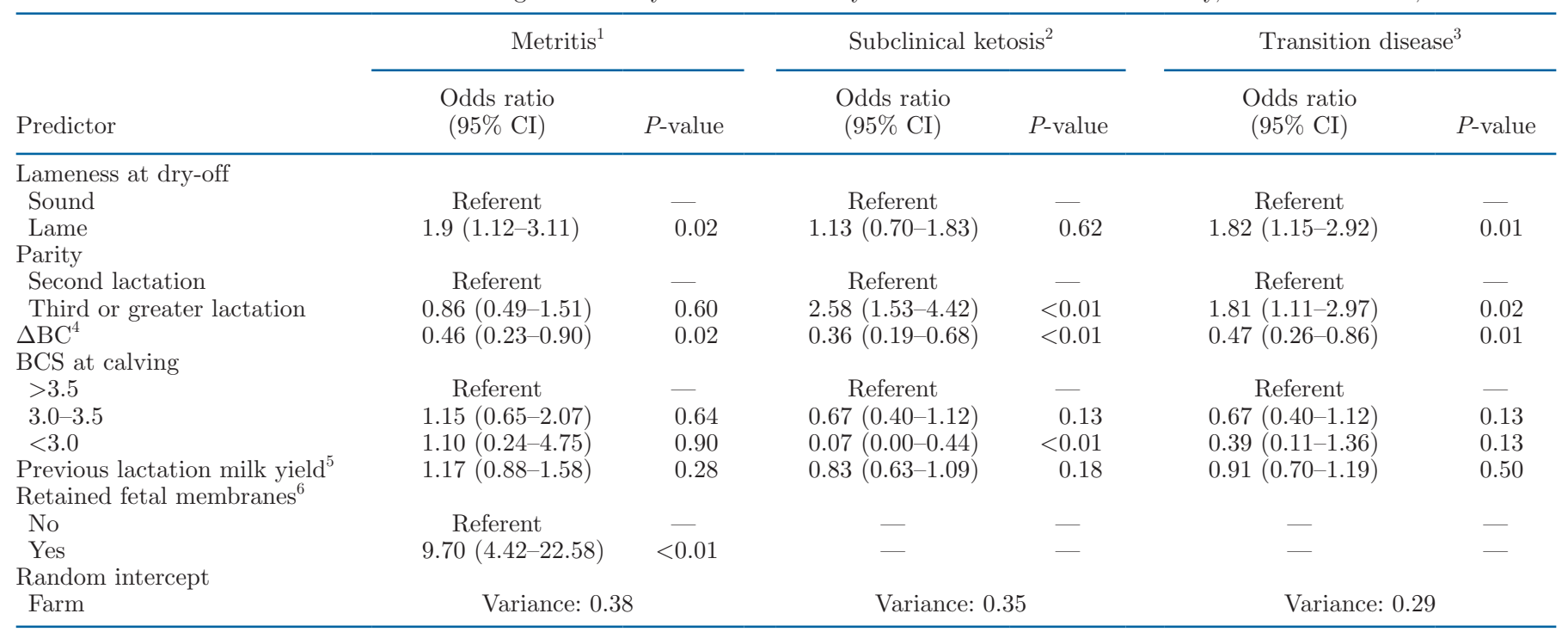

${ }^{1}$ Positive if vaginal discharge was red/brown, watery, and had a fetid smell on at least 1 health check.

${ }^{2}$ Positive if blood BHB $\geq 1.2 \mathrm{mmol} / \mathrm{L}$ on at least 1 health check.

${ }^{3}$ Any of the following: subclinical ketosis, metritis, retained fetal membranes, hypocalcemia, displaced abomasum.

${ }^{4}$ Change in BCS from dry-off to calving; a 1-unit change indicates that a cow gained 1 BCS point over the dry period.

${ }^{5}$ Scaled variable: a 1-unit change equals a change of 1 standard deviation from the mean previous lactation milk production from all enrolled cows.

${ }^{6}$ Retained fetal membranes was not included as predictor in the models for subclinical ketosis or transition disease. Data for retained fetal membranes were collected from farm records.

Table 4. Parameters from the models evaluating lameness as a predictor for metritis in 403 dairy cows from 6 dairy farms in the lower Fraser Valley, British Columbia, Canada

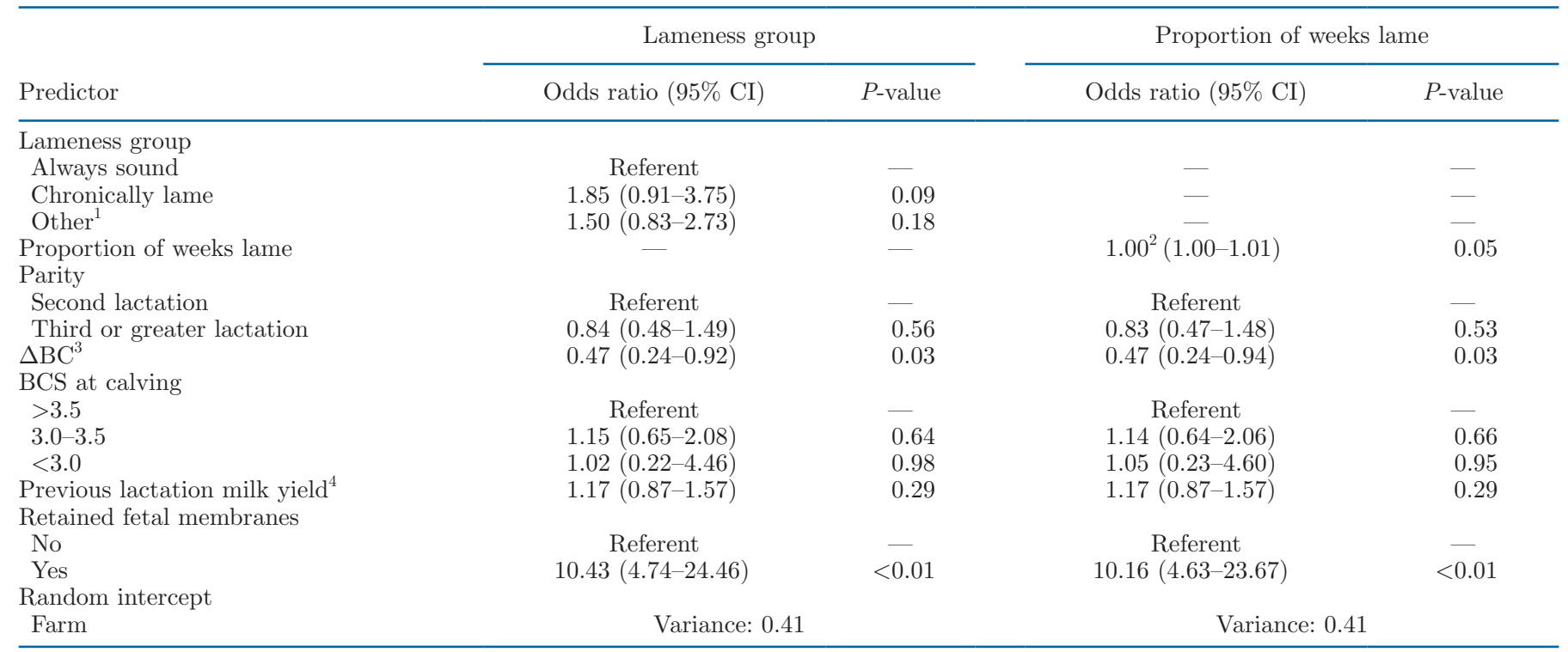

${ }^{1}$ Cows whose lameness status changed during the dry period.

${ }^{2}$ Adjusted odds for each $10 \%$ increase in weeks lame during the dry period $=1.07$.

${ }^{3}$ Change in BCS from dry-off to calving; a 1-unit change indicates that a cow gained 1 BCS point over the dry period.

${ }^{4}$ Scaled variable: a 1-unit change equals a change of 1 standard deviation from the mean previous lactation milk production from all enrolled cows. 
Table 5. Parameters from the models evaluating lameness as a predictor for subclinical ketosis ${ }^{1}$ in 404 dairy cows from 6 dairy farms in the lower Fraser Valley, British Columbia, Canada

\begin{tabular}{|c|c|c|c|c|}
\hline \multirow[b]{2}{*}{ Predictor } & \multicolumn{2}{|c|}{ Lameness group } & \multicolumn{2}{|c|}{ Proportion of weeks lame } \\
\hline & Odds ratio $(95 \% \mathrm{CI})$ & $P$-value & Odds ratio $(95 \% \mathrm{CI})$ & $P$-value \\
\hline Always sound & Referent & & - & - \\
\hline Chronically lame & $1.62(0.84-3.15)$ & 0.15 & - & - \\
\hline Other $^{2}$ & $1.28(0.75-2.20)$ & 0.38 & - & - \\
\hline Proportion of weeks lame & $1.20(0.10 .20)$ & - & $1.00^{3}(1.00-1.01)$ & 0.13 \\
\hline \multicolumn{5}{|l|}{ Parity } \\
\hline Third or greater lactation & $2.39(1.40-4.13)$ & $<0.01$ & $2.37(1.39-4.10)$ & $<0.01$ \\
\hline$\Delta \mathrm{BC}^{4}$ & $0.37(0.19-0.68)$ & $<0.01$ & $0.37(0.19-0.68)$ & $<0.01$ \\
\hline \multicolumn{5}{|l|}{ BCS at calving } \\
\hline$>3.5$ & Referent & - & Referent & - \\
\hline $3.0-3.5$ & $0.65(0.39-1.09)$ & 0.10 & $0.64(0.38-1.08)$ & 0.10 \\
\hline$<3.0$ & $0.06(0.00-0.41)$ & 0.01 & $0.06(0.00-0.42)$ & $<0.01$ \\
\hline Previous lactation milk yield ${ }^{5}$ & $0.84(0.63-1.10)$ & 0.20 & $0.84(0.63-0.10)$ & 0.20 \\
\hline
\end{tabular}

${ }^{1}$ Positive if blood $\mathrm{BHB} \geq 1.2 \mathrm{mmol} / \mathrm{L}$ on at least 1 health check.

${ }^{2}$ Cows whose lameness status changed during the dry period.

${ }^{3}$ Adjusted odds for each $10 \%$ increase in weeks lame during the dry period $=1.05$.

${ }^{4}$ Change in BCS from dry-off to calving; a 1-unit change indicates that a cow gained 1 BCS point over the dry period.

${ }^{5}$ Scaled variable: a 1-unit change equals a change of 1 standard deviation from the mean previous lactation milk production from all enrolled cows.

lactation. Body condition score at calving $(\leq 3.5$; OR $0.9 ; 95 \%$ CI: 0.4 to $2.1 ; P=0.76)$ and previous milk production (OR 0.8; 95\% CI: 0.5 to $1.1 ; P=0.23$ ) were not associated with the odds of SCK.
A $1 \mathrm{~h}$ increase in average feeding time during the close-up period also reduced the odds of TD by 0.7 times (95\% CI: 0.5 to $1.0 ; P=0.05)$. Third lactation or higher (OR 1.5; 95\% CI: 0.7 to $3.4 ; P=0.30$ ), BCS

Table 6. Parameters from the models evaluating lameness as a predictor for transition disease ${ }^{1}$ in 404 dairy cows from 6 dairy farms in the lower Fraser Valley, British Columbia, Canada

\begin{tabular}{|c|c|c|c|c|}
\hline \multirow[b]{2}{*}{ Predictor } & \multicolumn{2}{|c|}{ Lameness group } & \multicolumn{2}{|c|}{ Proportion of weeks lame } \\
\hline & Odds ratio $(95 \% \mathrm{CI})$ & $P$-value & Odds ratio $(95 \% \mathrm{CI})$ & $P$-value \\
\hline Always sound & Referent & & - & - \\
\hline Chronically lame & $2.22(1.19-4.22)$ & 0.01 & - & - \\
\hline Other $^{2}$ & $1.48(0.90-2.44)$ & 0.12 & - & - \\
\hline Proportion of weeks lame & - & - & $1.01^{3}(1.00-1.01)$ & $<0.01$ \\
\hline Third or greater lactation & $1.73(1.06-2.86)$ & 0.03 & $1.70(1.04-2.81)$ & 0.04 \\
\hline$\Delta \mathrm{BC}^{4}$ & $0.49(0.27-0.88)$ & 0.02 & $0.49(0.27-0.88)$ & 0.02 \\
\hline \multicolumn{5}{|l|}{ BCS at calving } \\
\hline$>3.5$ & Referent & - & Referent & - \\
\hline $3.0-3.5$ & $0.67(0.39-1.12)$ & 0.12 & $0.66(0.39-1.10)$ & 0.11 \\
\hline$<3.0$ & $0.35(0.10-1.23)$ & 0.10 & $0.37(0.10-1.37)$ & 0.12 \\
\hline Previous lactation milk yield ${ }^{5}$ & $0.91(0.69-1.18)$ & 0.48 & $0.91(0.69-1.18)$ & 0.48 \\
\hline
\end{tabular}

${ }^{1}$ Any of the following: subclinical ketosis, metritis, retained fetal membranes, hypocalcemia, or displaced abomasum within 3 wk of calving.

${ }^{2}$ Cows whose lameness status changed during the dry period.

${ }^{3}$ Adjusted odds for each $10 \%$ increase in weeks lame during the dry period $=1.09$.

${ }^{4}$ Change in BCS from dry-off to calving; a 1-unit change indicates that a cow gained 1 BCS point over the dry period.

${ }^{5}$ Scaled variable: a 1-unit change equals a change of 1 standard deviation from the mean previous lactation milk production from all enrolled cows. 
$(\leq 3.5$; OR 0.6 ; $95 \%$ CI: 0.3 to $1.4 ; P=0.24)$, and previous lactation milk production (OR $0.9 ; 95 \%$ CI: 0.6 to $1.2 ; P=0.45)$ were not associated with changes in odds of TD. The trends of feeding time during the dry period by TD are presented on Figure 4 .

Lameness and TD After Controlling for Covariates. When modeling the residuals from the multilevel logistic regression on TD, lameness group (always sound, chronically lame, and other) further explained residual variance (model statistics: $F=3.14 ; 2$ and 151 df; $P=0.05$; adjusted $\mathrm{R}^{2}=0.03$ ).

Factors Associated with $\triangle B C$. We found no clear association between lameness group and $\triangle \mathrm{BC}$ (see Figure 5). Compared with cows that remained sound during the dry period, the $\triangle \mathrm{BC}$ for chronically lame cows and cows that changed lameness status was -0.7 BCS
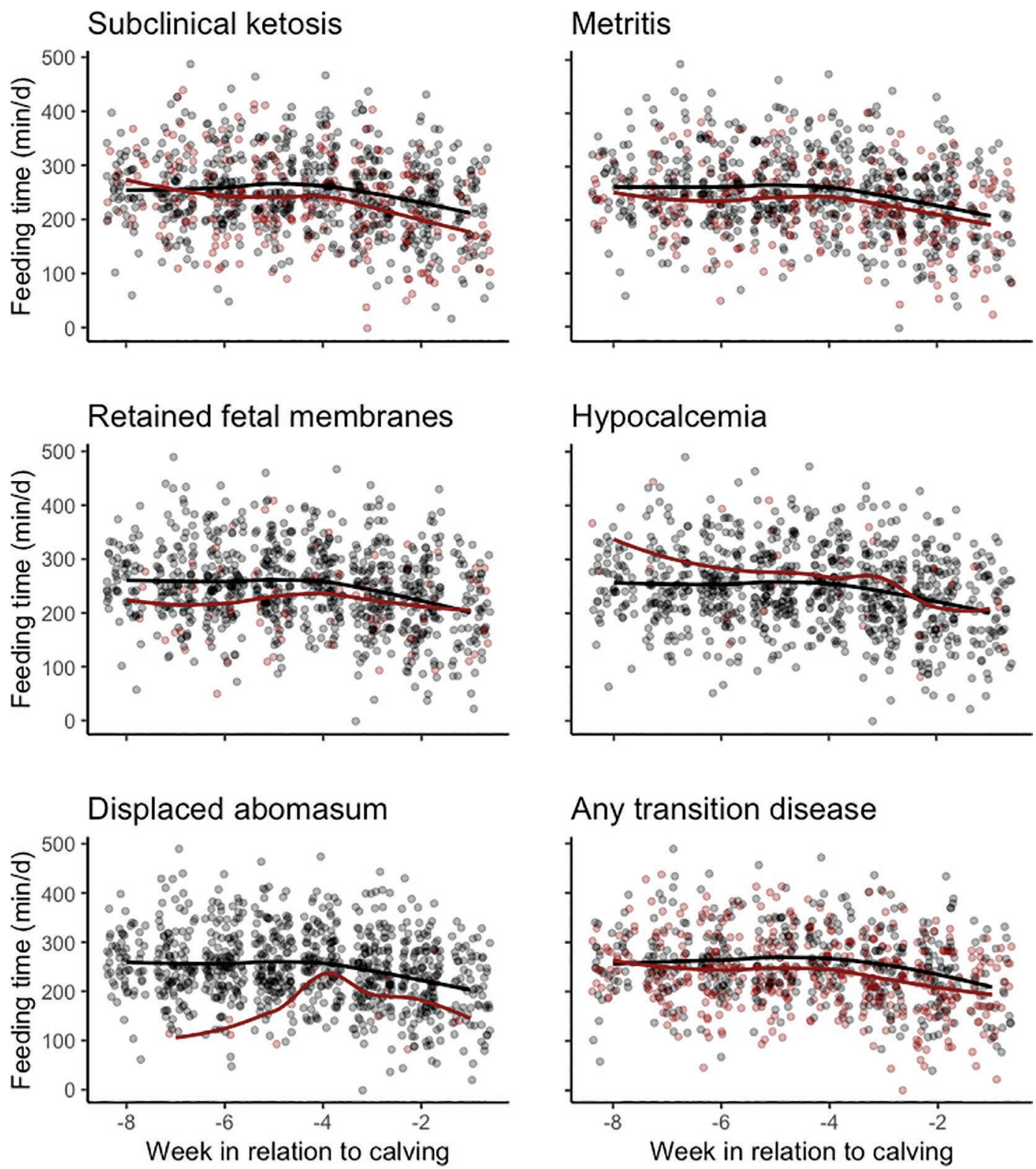

\section{Any transition disease}

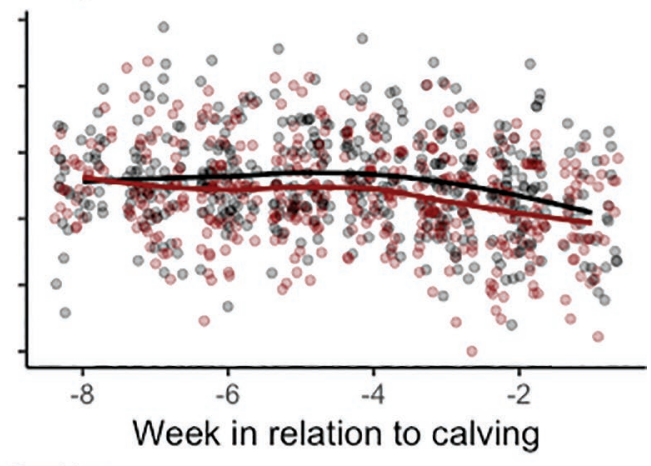

Figure 4. Descriptive data for feeding time during the dry period by transition disease category, based on the assessment of 159 dry cows from 5 commercial freestall dairy farms in the lower Fraser Valley, British Columbia, Canada. Each dot represents the measured feeding time of each cow observed each week. Dots were jittered using the geom_jitter function, and lines are estimated using the loess method from the geom_smooth function (ggplot2 package; Wickham, 2016). Gray dots and lines represent data from cows that were not diagnosed with disease. Red dots and lines represent data from cows that were diagnosed with disease. Transition disease included one or a combination of subclinical ketosis, metritis, retained fetal membranes, hypocalcemia, and displaced abomasum recorded within 3 wk after calving. 


\section{BCS category 审 fat 审 good 审 thin at dry-off}

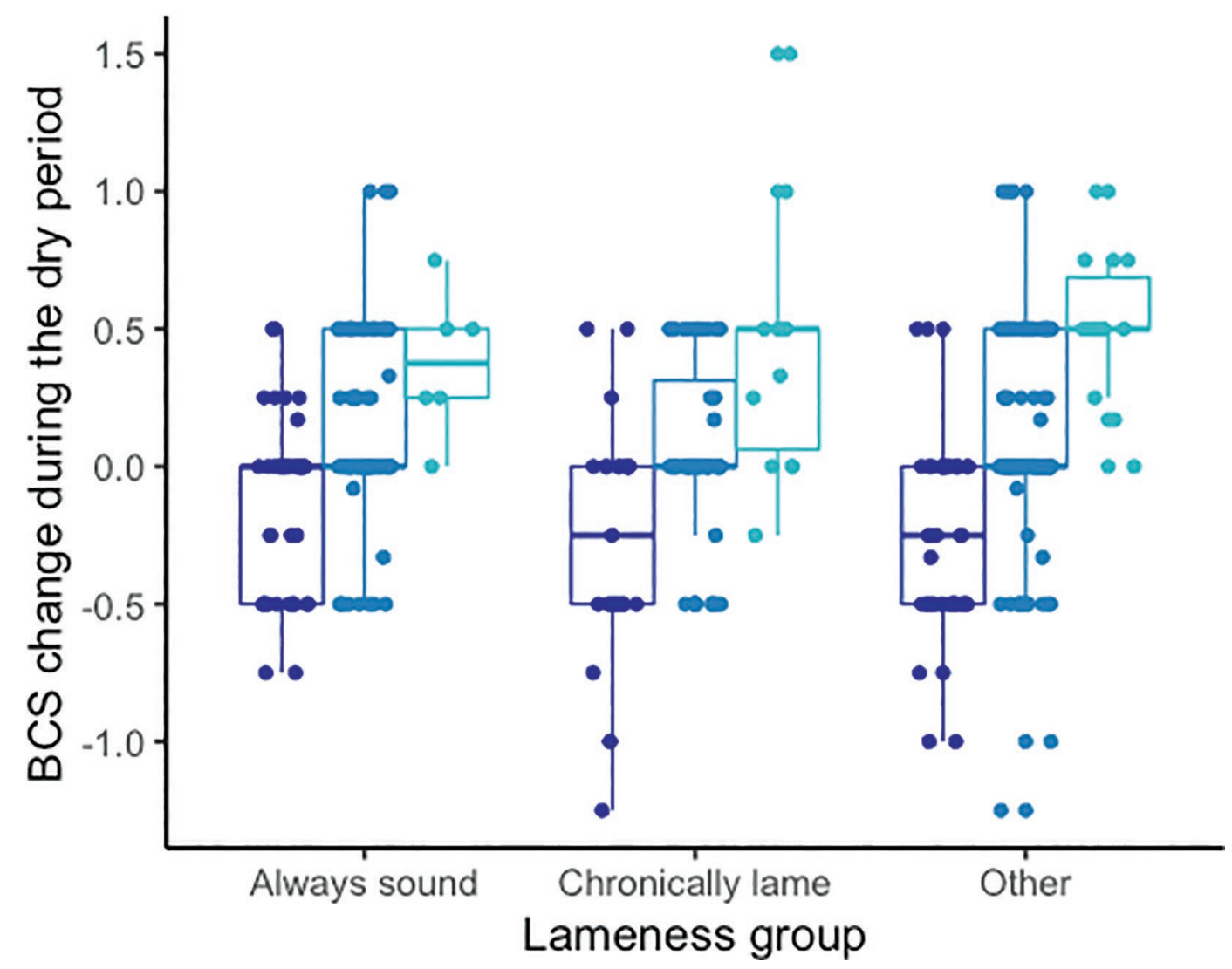

Figure 5. Boxplot showing body condition change during the dry period in relation to BCS at dry-off and lameness group. Data are from 426 dry cows from 6 commercial freestall dairy farms in the lower Fraser Valley, British Columbia, Canada. Each dot represents the measured BCS for each cow. Body condition score was categorized as fat $(>3.5)$, good (3.0 to 3.5), and thin $(<3.0)$. The lameness category "other" included cows whose lameness status changed during the dry period. Lameness group was not associated with body condition change during the dry period. Body condition score at dry-off was associated with body condition change; fat cows lost BCS during the dry period, and thin and good BCS cows gained BCS.

points (95\% CI: -0.17 to $0.02 ; P=0.12$ ) and $-0.7 \mathrm{BCS}$ points (95\% CI: -0.15 to $0.01 ; P=0.08)$, respectively. Cows that were thin and cows that had good BCS at dry-off gained BCS $(0.7,95 \%$ CI: 0.5 to $0.8, P<0.01$; and $0.4,95 \%$ CI: 0.3 to $0.4, P<0.01$, respectively) during the dry period compared with cows that were fat at dry-off; see Figure 5. For each day dry, cows increased their BCS 0.003 points (95\% CI: 0.001 to 0.006 ; $P<0.01$ ). Parity (multiparous $0.1 ; 95 \%$ CI: -0.6 to 0.09 BCS points; $P=0.76$ ) and previous lactation milk production $(-0.007 ; 95 \%$ CI: -0.05 to $0.03 ; P=0.75)$ were not associated with $\triangle \mathrm{BC}$.

On the model using the subsample of cows $(\mathrm{n}=159)$ assessed for feeding time, feeding time was positively associated with $\triangle \mathrm{BC}$ when average feeding time was $\leq 4 \mathrm{~h} / \mathrm{d}$ : an extra hour of feeding was associated with a 0.2 -point increase in $\triangle \mathrm{BC}(95 \%$ CI: 0.01 to $0.4 ; P$ $=0.05$; see Figure 6 ), but for average feeding time $>4$ $\mathrm{h} / \mathrm{d}$, we found no relationship between feeding time and $\triangle \mathrm{BC}(-0.08$ points; $95 \% \mathrm{CI}:-0.7$ to $0.7 ; P=$ 0.22 ; see Figure 6). Similarly, as described above, in the subsample of cows, cows that were thin and cows with good BCS at dry-off gained BCS (0.8 points, $95 \%$ CI: 0.6 to $1.1, P<0.01$; and 0.4 points, $95 \%$ CI: 0.2 to $0.4, P<0.01$, respectively) through the dry period compared with fat cows. Number of days dry (0.003; $95 \%$ CI: -0.00 to $0.01 ; P=0.11$ ), parity (multiparous $-0.06 ; 95 \%$ CI: -0.2 to $0.1 ; P=0.35)$, and previous lactation milk production $(0.02 ; 95 \%$ CI: -0.05 to 0.08 ; $P=0.52)$ were not associated with $\triangle \mathrm{BC}$. 


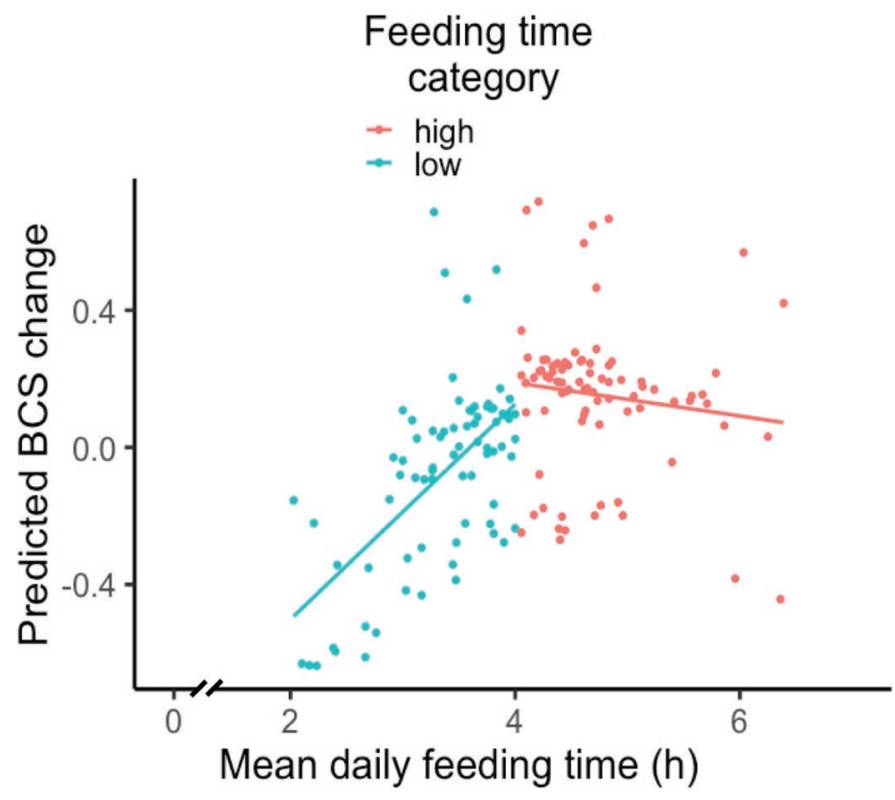

Figure 6. Interaction plot showing estimated body condition change during the dry period depending on average time spent eating during the dry period for 159 dry cows from 5 commercial freestall dairy farms in the lower Fraser Valley, British Columbia, Canada. Each dot represents the estimated body condition change (y-axis) along the average time spent feeding per day (x-axis). Lines represent the linear relationship between the variables, splitting average feeding time into 2 categories: high (red) and low (blue).

\section{DISCUSSION}

Our results support the hypothesis that lameness during the dry period is associated with TD. Lameness identified 2 mo before calving was associated with increased risk of $\mathrm{TD}$, highlighting the importance of screening cows for lameness around dry-off.

We partially explored the causal mechanism through which lameness relates to transition health as proposed by Calderon and Cook (2011); namely, that lameness reduces feeding time and consequently DMI. In a study similar to ours, researchers from Germany also found that cows decreased their feeding time when they became lame (Grimm et al., 2019), albeit with a magnitude 3 times greater $(-65 \mathrm{~min} / \mathrm{d}$ when lame) than in our study (-19 min/d when lame). The differences in feeding time between their study and ours may be due to reporting differences (their study reported only raw values rather than predicted values), breed difference (Simmental cows vs. Holstein cows) and differences in lactational stages (lactating vs. nonlactating cows). A cross-sectional study by González et al. (2008) reported a reduction of $19 \mathrm{~min} / \mathrm{d}$ in average feeding time of lame cows compared with non-lame cows. However, they included only severe lameness cases, whereas we included milder cases of lameness. Another study com- paring non-lame with moderately lame cows also found that lame animals had reduced feeding time, but no effect size was reported (Weigele et al., 2018). Together, these studies highlight that lameness is associated with reduced feeding time, suggesting that lame cows also have lower DMI (Bach et al., 2007). Although reduced feeding time does not always result in lower DMI (e.g., Grimm et al., 2019), some studies have shown that increased feeding time and increased DMI are correlated (e.g., Johnston and DeVries, 2018). Given that we were not able to measure DMI and that most previous studies conducted on commercial farms considered only lactating cows, further research on this behavior in dry cows is warranted.

Reduced feeding time during the weeks before calving was associated with SCK and TD, but not metritis. The lack of association between feeding time and metritis contradicts previous findings (Urton et al., 2005; Huzzey et al., 2007). Recently, Neave et al. (2018) conducted a study in the same experimental farm as the one used for the previous studies of Urton et al. (2005) and Huzzey et al. (2007), and also failed to corroborate their findings. Neave et al. (2018) argued that the differences in findings could be due to the fact that Huzzey et al. (2007) did not screen for SCK, which could have confounded the results because SCK has been associated with changes in feeding activity (Goldhawk et al., 2009). To explore the hypothesis proposed by Neave et al. (2018), we included (data not shown) SCK as a predictor in the metritis and feeding time model, and we were unable to detect any association between feeding time and metritis incidence, even when controlling for SCK. Huzzey et al. (2007) did not report if cows were diagnosed for lameness, and Neave et al. (2018) included only sound cows in their analysis. We did not include lameness as a predictor in our model for metritis and feeding time because feeding time would have become an intervening variable in the association between lameness and metritis. However, our results showing that lame cows spent less time feeding may partially explain the discrepancy between the results reported by Neave et al. (2018) and Huzzey et al. (2007), given that Huzzey et al. (2007) did not screen cows for lameness. Regarding SCK, our results were in line with those reported by Goldhawk et al., (2009), who reported that cows feeding less before calving were more likely to develop SCK. Neave et al. (2018) did not find differences in feeding time during the precalving period for cows with both SCK and metritis compared with healthy cows. Although we did not specifically combine SCK and metritis, cows with a TD spent less time feeding during the dry period.

Uterine diseases and SCK have been associated with BCS loss during the dry period (Kaufman et al., 2016; 
Chebel et al., 2018), which in turn is associated with BCS around dry-off (Chebel et al., 2018). In addition to corroborating previous findings that changes in BCS are associated with BCS at dry-off (Hoedemaker et al., 2009; Chebel et al., 2018), we were able to evaluate the association between lameness and body condition loss during the dry period; surprisingly, lameness was not associated with body condition loss. Some have suggested that cows naturally change BCS through homeorhetic mechanisms (Bauman and Currie, 1980; Roche et al., 2009), which, we speculate, may have had more influence on body condition changes than lameness. Based on our findings and those ones described by Chebel et al. (2018), it seems that monitoring BCS throughout lactation with the goal of achieving moderate BCS at dry-off may be beneficial for transition health. This strategy has been tested in grazing cows by comparing cows that had their BCS experimentally manipulated to achieve moderate BCS at dry-off to cows that had slightly higher BCS at dry-off; the animals with lower BCS had better metabolic (Roche et al., 2015) and immune status (Crookenden et al., 2017) during the transition period.

Independent of $\triangle \mathrm{BC}$, lameness during the dry period was associated with TD. Chronically lame cows tended to be more likely to develop metritis, and we found an association between proportion of weeks lame during the dry period and metritis development. We found a similar result for TD. These results explain our findings that lameness around dry-off is associated with metritis and TD, because cows that were lame around dry-off often continued to be lame during the dry period. Using only 1 lameness assessment within the 3 wk before calving, Vergara et al. (2014) reported an increased likelihood for severely lame, but not moderately lame, cows to be treated for TD in the post-calving period. The use of cross-sectional data to categorize cows as moderately lame may result in a high proportion of false positives Eriksson et al. (2020), biasing the estimates toward the null (Dohoo et al., 2012) and perhaps explaining the lack of association for moderate lameness reported by Vergara et al. (2014).

Lameness was not independently associated with SCK. Similarly, Kaufman et al. (2016) did not retain lameness in their final model exploring risk factors for SCK. This was not unexpected, given that thin cows have a lower likelihood of SCK (Vanholder et al., 2015) and are likely to experience repeated cases of lameness (Randall et al., 2015). For this reason, we explored the interplay between lameness and BCS at calving on the occurrence of SCK. From a separate analysis of the subgroup of cows that were fat at calving, our results suggest that fat cows that are also chronically lame during the dry period have an increased likelihood of developing SCK postpartum compared with sound fat cows. Further studies on SCK and lameness should account for this relationship by exploring the interaction between BCS and lameness status.

We evaluated the additive effects of body condition loss during the dry period and BCS at calving on metritis, SCK, and TD. We found that both $\triangle \mathrm{BC}$ and BCS at calving were independently associated with likelihood of SCK. Cows that are overconditioned around calving have a higher risk of SCK (e.g., Vanholder et al., 2015). Although Kaufman et al. (2016) also reported an effect of $\triangle \mathrm{BC}$ on the likelihood of SCK, they limited their measures of change in BCS from 3 weeks before calving to 2 weeks after calving, which meant that changes in BCS may have been a consequence of SCK.

Change in body condition was associated with the likelihood of cows developing metritis and TD, a similar finding to that of Chebel et al. (2018), who found an association between body condition loss during the dry period and increased likelihood of uterine diseases. Previous studies have described low BCS at calving as a risk factor for uterine disease (Duffield et al., 2009; Dubuc et al., 2010). In our study, low BCS at calving was not associated with metritis or TD. We speculate that the higher risk for cows with low BCS to develop uterine diseases after calving reported previously (Duffield et al., 2009; Dubuc et al., 2010) may have been due to an association between excessive body condition loss during the dry period and low body condition at calving (Chebel et al., 2018).

Chronic lameness during the dry period explained some of the variation in the likelihood of TD even after controlling for $\triangle \mathrm{BC}$, average feeding time during the close-up period, parity, milk production, and BCS at calving. This finding provides some evidence that lameness may be related to TD through a different pathway than feeding time. Given that lame cows have a higher level of inflammation (Tadich et al., 2013), this could lead to an increased susceptibility to TD (see review by Bradford et al., 2015). Studies on haptoglobin levels (a marker for inflammation) in prepartum sound and lame cows may provide additional insights on the interplay between lameness and transition period diseases.

\section{CONCLUSIONS}

Lameness at dry-off was associated with increased odds of metritis and TD. These results were further supported by our exploratory analyses, showing that chronic lameness during the dry period was associated with higher odds of TD. One of the mechanisms through which lameness may be associated with TD is through decreased feeding time; throughout the dry period, lame cows spent less time feeding than sound cows, and 
lower feeding time was in turn associated with higher odds of TD. Independent of lameness, body condition loss during the dry period was also associated with increased odds of transition period diseases. Moreover, body condition loss was associated with BCS at dry-off; cows that were fat at dry-off lost body condition, and thin cows gained body condition during the dry period. These results suggest that reducing lameness during the dry period and avoiding overconditioning at dry-off may improve transition health.

\section{ACKNOWLEDGMENTS}

We thank Samantha Jung, Paige Macdonald, and Wali Sahar (Animal Welfare Program) for their help during data collection, the participating farmers for their time and allowing us to conduct this project on their properties, the hoof trimmers at AR-PE Hoof Trimming Ltd. (Abbotsford, BC, Canada), and Martin Stigge (Vancouver, BC, Canada) for helping with software development and R code support. During this project RRD was supported by the Science Without Borders Program (CNPq - National Council for Scientific and Technological Development, Brazil) and HKE was supported by Tetra-Laval through the SwedenAmerica Foundation (Stockholm, Sweden). Funding for this project has been provided by the British Columbia Dairy Association through the Dairy Industry Research and Education Committee, and the Agriculture and Agri-Food Canada and the British Columbia Ministry of Agriculture through the Canada-British Columbia Agri-Innovation Program under Growing Forward 2, a federal-provincial-territorial initiative. The program is delivered by the Investment Agriculture Foundation of British Columbia. Opinions expressed in this document are those of the author and not necessarily those of the Governments of Canada and British Columbia or the Investment Agriculture Foundation of British Columbia. The Governments of Canada and British Columbia, and the Investment Agriculture Foundation of British Columbia, and their directors, agents, employees, or contractors will not be liable for any claims, damages, or losses of any kind whatsoever arising out of the use of, or reliance upon, this information. General funding for the Animal Welfare Program is provided by the Canada's Natural Sciences and Engineering Research Council Industrial Research Chair Program (Ottawa, ON, Canada) with contributions from Dairy Farmers of Canada (Ottawa, ON, Canada), the British Columbia Dairy Association (Burnaby, BC, Canada), Westgen Endowment Fund (Milner, BC, Canada), Intervet Canada Corporation (Kirkland, QC, Canada), Zoetis (Kirkland, QC, Canada), Novus International Inc.
(Oakville, ON, Canada), the British Columbia Cattle Industry Development Fund (Kamloops, BC, Canada), Alberta Milk (Edmonton, AB, Canada), Valacta (St Anne-de-Bellevue, QC, Canada) and CanWest DHI (Guelph, ON, Canada).

\section{REFERENCES}

Bach, A., M. Dinarés, M. Devant, and X. Carré. 2007. Associations between lameness and production, feeding and milking attendance of Holstein cows milked with an automatic milking system. J. Dairy Res. 74:40-46. https://doi.org/10.1017/S0022029906002184.

Bauman, D. E., and B. W. Currie. 1980. Partitioning of nutrients during pregnancy and lactation: a review of mechanisms involving homeostasis and homeorhesis. J. Dairy Sci. 63:1514-1529. https:// doi.org/10.3168/jds.S0022-0302(80)83111-0.

Bell, A. W. 1995. Regulation of organic nutrient metabolism during transition from late pregnancy to early lactation. J. Anim. Sci. 73:2804-2819. https://doi.org/10.2527/1995.7392804x.

Bertoni, G., E. Trevisi, X. Han, and M. Bionaz. 2008. Effects of inflammatory conditions on liver activity in puerperium period and consequences for performance in dairy cows. J. Dairy Sci. 91:33003310. https://doi.org/10.3168/jds.2008-0995.

Bradford, B. J., K. Yuan, J. K. Farney, L. K. Mamedova, and A. J. Carpenter. 2015. Invited review: Inflammation during the transition to lactation: New adventures with an old flame. J. Dairy Sci. 98:6631-6650. https://doi.org/10.3168/jds.2015-9683.

Calderon, D. F., and N. B. Cook. 2011. The effect of lameness on the resting behavior and metabolic status of dairy cattle during the transition period in a freestall-housed dairy herd. J. Dairy Sci. 94:2883-2894. https://doi.org/10.3168/jds.2010-3855.

Chapinal, N., M. Carson, T. F. Duffield, M. Capel, S. Godden, M. Overton, J. E. P. Santos, and S. J. LeBlanc. 2011. The association of serum metabolites with clinical disease during the transition period. J. Dairy Sci. 94:4897-4903. https://doi.org/10.3168/jds $.2010-4075$.

Chapinal, N., A. M. de Passillé, J. Rushen, and S. Wagner. 2010. Automated methods for detecting lameness and measuring analgesia in dairy cattle. J. Dairy Sci. 93:2007-2013. https://doi.org/10 $.3168 /$ jds.2009-2803.

Chebel, R. C., L. G. D. Mendonça, and P. S. Baruselli. 2018. Association between body condition score change during the dry period and postpartum health and performance. J. Dairy Sci. 101:45954614. https://doi.org/10.3168/jds.2017-13732.

Contreras, G. A., and L. M. Sordillo. 2011. Lipid mobilization and inflammatory responses during the transition period of dairy cows. Comp. Immunol. Microbiol. Infect. Dis. 34:281-289. https://doi .org/10.1016/j.cimid.2011.01.004.

Crookenden, M. A., C. G. Walker, A. Heiser, A. Murray, V. S. R. Dukkipati, J. K. Kay, S. Meier, K. M. Moyes, M. D. Mitchell, J. J. Loor, and J. R. Roche. 2017. Effects of precalving body condition and prepartum feeding level on gene expression in circulating neutrophils. J. Dairy Sci. 100:2310-2322. https://doi.org/10.3168/ jds.2016-12105.

Dohoo, I. R., M. Wayne, and H. Stryhn. 2012. Methods in Epidemiologic Research. 2nd ed. VER Inc, Charlottetown, Canada.

Dubuc, J., T. F. Duffield, K. E. Leslie, J. S. Walton, and S. J. Leblanc. 2010. Risk factors for postpartum uterine diseases in dairy cows. J. Dairy Sci. 93:5764-5771. https://doi.org/10.3168/jds.2010-3429.

Duffield, T. 2000. Subclinical ketosis in lactating dairy cattle. Vet. Clin. North Am. Food Anim. Pract. 16:231-253. https://doi.org/ 10.1016/S0749-0720(15)30103-1.

Duffield, T. F., K. D. Lissemore, B. W. McBride, and K. E. Leslie. 2009. Impact of hyperketonemia in early lactation dairy cows on health and production. J. Dairy Sci. 92:571-580. https://doi.org/ $10.3168 /$ jds.2008-1507.

Duffield, T. F., D. Sandals, K. E. Leslie, K. Lissemore, B. W. McBride, J. H. Lumsden, P. Dick, and R. Bagg. 1998. Efficacy of monensin 
for the prevention of subclinical ketosis in lactating dairy cows. J. Dairy Sci. 81:2866-2873. https://doi.org/10.3168/jds.S0022 -0302(98)75846-1.

Eriksson, H. K., R. R. Daros, M. A. G. von Keyserlingk, and D. M. Weary. 2020. Effects of case definition and assessment frequency on lameness incidence estimates. J. Dairy Sci. 103:638-648. https: //doi.org/10.3168/jds.2019-16426.

Ferguson, J. D., D. T. Galligan, and N. Thomsen. 1994. Principal descriptors of body condition score in Holstein cows. J. Dairy Sci. 77:2695-2703. https://doi.org/10.3168/jds.S0022-0302(94)77212 -X.

Flower, F. C., and D. M. Weary. 2006. Effect of hoof pathologies on subjective assessments of dairy cow gait. J. Dairy Sci. 89:139-146. https://doi.org/10.3168/jds.S0022-0302(06)72077-X.

Goldhawk, C., N. Chapinal, D. M. Veira, D. M. Weary, and M. A. G. von Keyserlingk. 2009. Prepartum feeding behavior is an early indicator of subclinical ketosis. J. Dairy Sci. 92:4971-4977. https:/ /doi.org/10.3168/jds.2009-2242.

González, L. A., B. J. Tolkamp, M. P. Coffey, A. Ferret, and I. Kyriazakis. 2008. Changes in feeding behavior as possible indicators for the automatic monitoring of health disorders in dairy cows. J. Dairy Sci. 91:1017-1028. https://doi.org/10.3168/jds.2007-0530.

Grimm, K., B. Haidn, M. Erhard, M. Tremblay, and D. Döpfer. 2019. New insights into the association between lameness, behavior, and performance in Simmental cows. J. Dairy Sci. 102:2453-2468. https://doi.org/10.3168/jds.2018-15035.

Grummer, R. R. 1995. Impact of changes in organic nutrient metabolism on feeding the transition dairy cow. J. Anim. Sci. 73:28202833.

Grummer, R. R., D. G. Mashek, and A. Hayirli. 2004. Dry matter intake and energy balance in the transition period. Vet. Clin. North Am. Food Anim. Pract. 20:447-470. https://doi.org/10.1016/j .cvfa.2004.06.013.

Hallgren, K. A. 2012. Computing inter-rater reliability for observational data: An overview and tutorial. Tutor. Quant. Methods Psychol. 8:23-34.

Hammon, D. S., I. M. Evjen, T. R. Dhiman, J. P. Goff, and J. L. Walters. 2006. Neutrophil function and energy status in Holstein cows with uterine health disorders. Vet. Immunol. Immunopathol. 113:21-29. https://doi.org/10.1016/j.vetimm.2006.03.022.

Hayirli, A., and R. R. Grummer. 2004. Factors affecting dry matter intake prepartum in relationship to etiology of peripartum lipidrelated metabolic disorders: A review. Can. J. Anim. Sci. 84:337347. https://doi.org/10.4141/A03-122.

Hayirli, A., R. R. Grummer, E. V. Nordheim, and P. M. Crump. 2002. Animal and dietary factors affecting feed intake during the prefresh transition period in Holsteins. J. Dairy Sci. 85:3430-3443. https://doi.org/10.3168/jds.S0022-0302(02)74431-7.

Hoedemaker, M., D. Prange, and Y. Gundelach. 2009. Body condition change ante- and postpartum, health and reproductive performance in German Holstein cows. Reprod. Domest. Anim. 44:167173. https://doi.org/10.1111/j.1439-0531.2007.00992.x.

Huzzey, J. M., D. M. Veira, D. M. Weary, and M. A. G. von Keyserlingk. 2007. Prepartum behavior and dry matter intake identify dairy cows at risk for metritis. J. Dairy Sci. 90:3220-3233. https:/ /doi.org/10.3168/jds.2006-807.

Ingvartsen, K. L. 2006. Feeding- and management-related diseases in the transition cow. Anim. Feed Sci. Technol. 126:175-213. https:/ /doi.org/10.1016/j.anifeedsci.2005.08.003.

Johnston, C., and T. J. DeVries. 2018. Short communication: Associations of feeding behavior and milk production in dairy cows. J. Dairy Sci. 101:3367-3373. https://doi.org/10.3168/jds.2017-13743.

Kaufman, E. I., S. J. LeBlanc, B. W. McBride, T. F. Duffield, and T. J. DeVries. 2016. Association of rumination time with subclinical ketosis in transition dairy cows. J. Dairy Sci. 99:5604-5618. https: //doi.org/10.3168/jds.2015-10509.

LeBlanc, S. 2010. Monitoring metabolic health of dairy cattle in the transition period. J. Reprod. Dev. 56:S29-S35. https://doi.org/10 $.1262 /$ jrd.1056s29

Macmillan, K., I. López Helguera, A. Behrouzi, M. Gobikrushanth, B. Hoff, and M. G. Colazo. 2017. Accuracy of a cow-side test for the diagnosis of hyperketonemia and hypoglycemia in lactating dairy cows. Res. Vet. Sci. 115:327-331. https://doi.org/10.1016/j.rvsc 2017.06.019.

McArt, J. A. A., D. V. Nydam, and G. R. Oetzel. 2012. Epidemiology of subclinical ketosis in early lactation dairy cattle. J. Dairy Sci. 95:5056-5066. https://doi.org/10.3168/jds.2012-5443.

Miguel-Pacheco, G. G., J. Kaler, J. Remnant, L. Cheyne, C. Abbott, A. P. French, T. P. Pridmore, and J. N. Huxley. 2014. Behavioural changes in dairy cows with lameness in an automatic milking system. Appl. Anim. Behav. Sci. 150:1-8. https://doi.org/10.1016/j applanim.2013.11.003.

Mitlöhner, F. M., J. L. Morrow-Tesch, S. C. Wilson, J. W. Dailey, and J. J. McGlone. 2001. Behavioral sampling techniques for feedlot cattle. J. Anim. Sci. 79:1189-1193.

Morin, P.-A., Y. Chorfi, J. Dubuc, J.-P. Roy, D. Santschi, and S. Dufour. 2017. Short communication: An observational study investigating inter-observer agreement for variation over time of body condition score in dairy cows. J. Dairy Sci. 100:3086-3090. https:/ /doi.org/10.3168/jds.2016-11872.

Mulligan. F. J., and M. L. Doherty. 2008. Production diseases of the transition cow. Vet. J. 176:3-9. https://doi.org/10.1016/j.tvjl.2007 .12 .018 .

Neave, H. W., J. Lomb, D. M. Weary, S. J. LeBlanc, J. M. Huzzey, and M. A. G. von Keyserlingk. 2018. Behavioral changes before metritis diagnosis in dairy cows. J. Dairy Sci. 101:4388-4399. https:// doi.org/10.3168/jds.2017-13078.

Ospina, P. A., D. V. Nydam, T. Stokol, and T. R. Overton. 2010 Evaluation of nonesterified fatty acids and $\beta$-hydroxybutyrate in transition dairy cattle in the northeastern United States: Critical thresholds for prediction of clinical diseases. J. Dairy Sci. 93:546554. https://doi.org/10.3168/jds.2009-2277.

Pinheiro, J. C., and E. C. Chao. 2006. Efficient Laplacian and adaptive Gaussian quadrature algorithms for multilevel generalized linear mixed models. J. Comput. Graph. Stat. 15:58-81. https://doi .org/10.1198/106186006X96962.

R Core Team. 2019. R: A language and environment for statistical computing. R Foundation for Statistical Computing,Vienna, Austria. Accessed Sep. 29, 2019. https://www.r-project.org/.

Randall, L. V., M. J. Green, M. G. G. Chagunda, C. Mason, S. C. Archer, L. E. Green, and J. N. Huxley. 2015. Low body condition predisposes cattle to lameness: An 8-year study of one dairy herd. J. Dairy Sci. 98:3766-3777. https://doi.org/10.3168/jds.2014-8863.

Randall, L. V., H. J. Thomas, J. G. Remnant, N. J. Bollard, and J. N. Huxley. 2019. Lameness prevalence in a random sample of UK dairy herds. Vet. Rec. 184:350. https://doi.org/10.1136/vr.105047.

Rathbun, F. M., R. S. Pralle, S. J. Bertics, L. E. Armentano, K. Cho, C. Do, K. A. Weigel, and H. M. White. 2017. Relationships between body condition score change, prior mid-lactation phenotypic residual feed intake, and hyperketonemia onset in transition dairy cows. J. Dairy Sci. 100:3685-3696. https://doi.org/10.3168/ jds.2016-12085.

Roche, J. R., N. C. Friggens, J. K. Kay, M. W. Fisher, K. J. Stafford, and D. P. Berry. 2009. Invited review: Body condition score and its association with dairy cow productivity, health, and welfare. J. Dairy Sci. 92:5769-5801. https://doi.org/10.3168/jds.2009-2431.

Roche, J. R., S. Meier, A. Heiser, M. D. Mitchell, C. G. Walker, M. A Crookenden, M. V. Riboni, J. J. Loor, and J. K. Kay. 2015. Effects of precalving body condition score and prepartum feeding level on production, reproduction, and health parameters in pasture-based transition dairy cows. J. Dairy Sci. 98:7164-7182. https://doi.org/ $10.3168 /$ jds.2014-9269.

RStudio Team. 2016. RStudio: Integrated development environment for R. RStudio, Inc., Boston, MA. https://www.rstudio.com/.

Sheldon, I. M., G. S. Lewis, S. LeBlanc, and R. O. Gilbert. 2006. Defining postpartum uterine disease in cattle. Theriogenology 65:1516-1530. https://doi.org/10.1016/j.theriogenology.2005.08 .021 .

Solano, L., H. W. Barkema, E. A. Pajor, S. Mason, S. J. LeBlanc, J. C. Zaffino Heyerhoff, C. G. R. Nash, D. B. Haley, E. Vasseur, D. Pellerin, J. Rushen, A. M. de Passillé, and K. Orsel. 2015. Prevalence of lameness and associated risk factors in Canadian Holstein- 
Friesian cows housed in freestall barns. J. Dairy Sci. 98:6978-6991. https://doi.org/10.3168/jds.2015-9652.

Sordillo, L. M., G. A. Contreras, and S. L. Aitken. 2009. Metabolic factors affecting the inflammatory response of periparturient dairy cows. Anim. Health Res. Rev. 10:53-63. https://doi.org/10.1017/ S1466252309990016.

Tadich, N., C. Tejeda, S. Bastias, C. Rosenfeld, and L. E. Green. 2013. Nociceptive threshold, blood constituents and physiological values in 213 cows with locomotion scores ranging from normal to severely lame. Vet. J. 197:401-405. https://doi.org/10.1016/j.tvjl .2013.01.029.

Urton, G., M. A. G. von Keyserlingk, and D. M. Weary. 2005. Feeding behavior identifies dairy cows at risk for metritis. J. Dairy Sci. 88:2843-2849. https://doi.org/10.3168/jds.S0022-0302(05)72965 -9 .

Vanholder, T., J. Papen, R. Bemers, G. Vertenten, and A. C. B. Berge. 2015. Risk factors for subclinical and clinical ketosis and association with production parameters in dairy cows in the Netherlands. J. Dairy Sci. 98:880-888. https://doi.org/10.3168/jds.2014-8362.

Venzon, D. J., and S. H. Moolgavkar. 1988. A method for computing profile-likelihood-based confidence intervals. J. R. Stat. Soc. Ser. C. Appl. Stat. 37:87-94.

Vergara, C. F., D. Döpfer, N. B. Cook, K. V. Nordlund, J. A. A. McArt, D. V. Nydam, and G. R. Oetzel. 2014. Risk factors for postpartum problems in dairy cows: Explanatory and predictive modeling. J. Dairy Sci. 97:4127-4140. https://doi.org/10.3168/jds .2012-6440.

Weber, C., C. Hametner, A. Tuchscherer, B. Losand, E. Kanitz, W. Otten, S. P. Singh, R. M. Bruckmaier, F. Becker, W. Kanitz, and H. M. Hammon. 2013. Variation in fat mobilization during early lactation differently affects feed intake, body condition, and lipid and glucose metabolism in high-yielding dairy cows. J. Dairy Sci. 96:165-180. https://doi.org/10.3168/jds.2012-5574.

Weigele, H. C., L. Gygax, A. Steiner, B. Wechsler, and J.-B. Burla. 2018. Moderate lameness leads to marked behavioral changes in dairy cows. J. Dairy Sci. 101:2370-2382. https://doi.org/10.3168/ jds.2017-13120.

Whay, H. R., A. J. F. Webster, and A. E. Waterman-Pearson. 2005. Role of ketoprofen in the modulation of hyperalgesia associated with lameness in dairy cattle. Vet. Rec. 157:729-733. https://doi .org/10.1136/vr.157.23.729.

Wickham, H. 2016. Ggplot2: Elegant Graphics for Data Analysis. Springer-Verlag, New York, NY.

\section{ORCIDS}

Ruan R. Daros (ํ) https://orcid.org/0000-0003-2331-1648

Marina A. G. von Keyserlingk ( ) https://orcid.org/0000-0002-1427 $-3152$ 